\title{
SIMULASI ANTRIAN PELAYANAN PADA GARDU TOL BINJAI
}

\author{
${ }^{1}$ Akim Manaor Hara Pardede, ${ }^{2}$ Herdianta, ${ }^{3}$ Suci Ramadani, ${ }^{4}$ Husnul Khair, \\ ${ }^{5}$ Siswan Syahputra \\ 1,3,4,5 STMIK KAPUTAMA, Jl. Veteran No. 4A-9A, Binjai, Sumatera Utara, Indonesia \\ ${ }^{2}$ SMK Negeri 1 Kutalimbaru, Sumatera Utara, Indonesia \\ Email: ${ }^{1}$ akimmhp@live.com
}

\begin{abstract}
Services performed by service providers must be maximized, so that customers get satisfaction in receiving services. The thing that affects service maximally is the limited available resources, so more research is needed about the queuing system that has gone so far. Binjai City already has a toll road and has been operating since 2018, so far the use of toll roads is still running smoothly, but it should be noted whether this toll road has been operating optimally or not optimally. Toll roads are an important part of the transportation system, toll roads not only function as a good choice to avoid traffic congestion, but also affect all traffic conditions for the metropolitan area. Congestion is currently not a priority issue on the Binjai-Medan toll road. From the results of the research conducted, information is obtained that the number of toll gates is still appropriate, namely 3 Substations, Probability of busy Substation $=<1$ means that for now the Toll Gate will not be long queues at the time of normal everyday conditions, and further analysis is needed in the following years, so that the possibility of a Toll Station can always be maximized.
\end{abstract}

Keywords: Queue, Simulation, Server Service, Toll Station.

\section{PENDAHULUAN}

Model persediaan stokastik merupakan model persediaan di mana pemintaan barang dan lead time memiliki sifat yang tidak dapat diprediksi/tidak pasti. Fasilitas-fasilitas pelayanan publik adalah merupakan salah satu fasilitas yang dibutuhkan oleh semua masyarakat, seperti pelayanan rumah sakit, jalan tol, dan administrasi lainnya (Purnomo \& Wulandari, 2017).

Masalah persediaan paling sesuai diselesaikan dengan pendekatan simulasi, yang berfungsi untuk meniru perilaku sistem nyata. Simulasi merupakan salah alat yang digunakan oleh manajemen untuk melakukan analisis perilaku kerja dari suatu sistem atau proses, model skenario alternatif berbasis simulasi dinamis yang dapat meminimalkan biaya dan memaksimalkan pemanfaatan sumber daya yang tersedia dalam proses pelayanan (Pasirulloh \& Suryani, 2017), oleh karena itu diperlukan simulasi dengan model stokastik pada yang dapat diaplikasikan dalam menganalisis karakteristik sistem (Simamora \& Jamaluddin, 2017).

Dalam hal memberikan pelayanan pada pelanggan akan mengakibatkan antrian yang panjang jika ternyata sumberdaya tidak mencukupi untuk melakukan pelayanan, antrian adalah kejadian pelanggan menunggu untuk memperoleh sebuah layanan (Saragih \& Pardede, 2018), dan antrian akan semakin panjang jika pelayananan tak kunjung juga diterima. (Andika \& Pardede, 2018).

Peningkatan pelayanan pemerintah bagi masyarakat Indonesia semakin ditingkatkan, pelayanan-pelayanan umum tersebut seperti pelayanan kesehatan, administratif kependudukan, layanan pendidikan, layanan transportasi, dan lain sebagainya. Layanan transportasi darat dilakukan dengan pembangunan jalan umum dan jalan tol. 
Jalan tol dibangun untuk menangani masalah kemacatan pda jalan umum akibat dari kepadatan kendaraan yang memakai jalan.

Kemacetan setiap hari yang terjadi dari Kota Binjai ke Medan atau sebaliknya adalah merupakan masalahah yang dihadapi sehari-hari, untuk itu pemerintah mengadakkan pembangunan Tol Binjai-Medan, tol Binjai-Medan resmi beroperasi pada bulan september 2017 yang terhubung sepanjang 10,6 KM. Pada saat memasuki gerbang tol maupun sistem pembayaran sekarang ini sudah menggunakan Non Tunai (E-Tol) sehingga mengurangi waktu pelayanan saat memasuki gardu tol, dimana jumlah kedatangan dalam antrian per gradu tol maksimumnya adalah 3 kendaraaan sebagai Standart Geometri Jalan Bebas Hambatan untuk jalan tol (DEPARTEMEN PEKERJAAN UMUM DIREKTORAT JENDERAL BINA MARGA, 2009), (Iskandar, 2012).

Dalam berbagai studi mengenai antrian pada gardu/gerbang tol akan memberikan kesimpulan untuk menambah jumlah gerbang tol, tetapi untuk memberikan kesimpulan ini harus dilakukan kajian mengenai permasalahnnya (Winarsih \& Kusumaningrum, 2013), permasalahan yang dibahas dalam penelitian ini adalah mengenai Standar Pelayanan Minimal (SMP) jalan tol BinjaiMedan, yang dimana pada saat ini masih jarang mengalami adanya antrian pada gerbang tol masuk maupun keluar, teapi penelitian ini menitik beratkan pembahasan pada kemampuan pelayanan pada tol Binjai-Medan.

Jalan tol merupakan bagian penting dari sistem transportasi, jalan tol tidak hanya berfungsi sebagai pilihan yang baik untuk menghindar dari kemacetan jalan umum, tetapi juga mempengaruhi seluruh kondisi trafik untuk wilayah metropolitan (Wang, Kim, Kim, \& Lee, 2017). Untung meningkatkan pelayanan jalan tol ide sistem kontrol akses trafik telah diajukan sebelumnya dalam berbagai penelitian. Pertama kali diperkenalkan oleh Akahane dan Kuwahara dalam sistem transportasi udara dengan tujuan untuk mengelola permintaan perjalanan dengan cara pemesanan terlebih dahulu (Akahane \& Kuwahara, 1996). Kemudian diusulkan prosedur pemesanan untuk mengontrol waktu keberangkatan kendaraan pribadi didahulukan dengan hasil pelayanan yang lebih baik (Wong, 1997). Feijter dalam penellitiannya juga menganjurkan sistem pemesanan dalam penggunaan jalan tol dan memberikan penjelasan bahwa sistem reservasi meningkatkan keandalan dan efisiensi sistem. Berikutnya diusulakan oelh Liu et al sistem pemesanan berbasis token dan algoritma penjadwalan real-time untuk memantau kondisi lalu lintas dan menjaga efisiensi jalur prioritas tinggi (Liu, Chan, Lee, Kapitanova, \& Son, 2013). Pelayanan jalan tol ini juga bisa dipadukan dengan sistem pelayanan transportasi yang digunakan oleh pasien dari rumah sakit sebagai upaya pemberian pelayanan prioritas bagi seluruh pasien rumah sakit yang dalam keadaan darurat (Akim Manaor Hara Pardede, Mawengkang, et al., 2018).

Data yang dikumpulkan dalam penelitian ini terdiri dari data primer dan data sekunder. Datadata yang diambil selama survei diantaranya data waktu pelayanan yang diambil pada saat kendaraan berhenti pada gerbang tol masuk dan keluar, waktu saat pemindai masuk dan keluar jalan tol, sampai kendaraan tersebut bergerak meninggalkan gerbang tol, dan data tingkat kedatangan kendaraan, dilakukan dengan menghitung jumlah kendaraan yang datang tiap 10 menit. Setelah data diperoleh, dilakukan uji kecocokan data. Uji kecocokan ini bertujuan untuk membandingkan frekuensi sebenarnya hasil pengamatan dengan hasil yang diharapkan berdasarkan model atau teoritis. Kemudian dilakukan uji Chi- Kuadrat yang digunakan untuk mengetahui diterima atau tidaknya suatu distribusi data. Perhitungan dan analisis data bertujuan untuk mengetahui nilai rata-rata tingkat kedatangan maupun waktu pelayanan yang selanjutnya digunakan untuk menentukan jumlah 
gerbang tol yang dibutuhkan, kapasitas gerbang tol, dan panjang antrian di gerbang tol Medan - Binjai.

Tujuan dari penelitian ini akan mendapatkan jumlah gardu tol yang sesuai dengan tingkat kedatangan kendaraan yang ada pada Gardu Tol Binjai.

\section{PUSTAKA}

Sistem antrian adalah merupakan dari proses yang diperhitungan semenjak pelanggan masuk kedalam sistem hingga keluar dari sistem. Untuk lebih memahami suatu sistem antrian diperlukan pengetahuan pada struktur sistem antrian yang akan diteliti, yaitu bagian yang memerlukan pelayanan yang selanjutnya disebut sebagai pelanggan (customer) dan bagian yang melayani pelanggan disebut sebagai pelayan (server). (A M H Pardede, Mawengkang, \& Situmorang, 2014).

Komponen utama pada teori antrian yang ada tiga, yaitu (A M H Pardede, 2013) :

a. Tingkat kedatangan

b. Tingkat pelayanan

c. Disiplin antrian

Yang berpengaruh sistem antrian terdiri dari beberapa komponen, yaitu (A M H Pardede, 2013) :

1. Distribusi Kedatangan

2. Distribusi Waktu Pelayanan

3. Fasilitas pelayanan

4. Disiplin pelayanan

5. Ukuran dalam antrian

6. Sumber pemanggilan

Sistem Pelayanan pada Gardu Tol dapat dilakukan secara sistem tertutup atau secara sistem terbuka dengan memperhatikan kepentingan pengguna dan efisiensi pengoperasian jalan tol serta kelancaran lalu lintas (PP No. 15 Th 2005, Pasal 39 ayat 1. Adapun sistem pelayanan pada Gardu tol saat ini terdiri dari beberapa sistem layanan, yaitu (Sodikin, 2006) :

1. Sistem Pelayanan dengan Uang Pas
2. Sistem Pengumpulan Elektonik atau Electronic Toll Collection

3. Sistem Pengumpulan Konvensional

4. Sistem Karcis Langganan Tol

5. Sistem Pelayanan Gardu Pelayanan Cepat

6. Sistem Pelayanan dengan Gardu Tandem

7. Sistem Pelayanan Kartu Prabayar

8. Sistem Pelayanan kartu kredit

9. Sistem Pelayanan Tarif Elastis

10. Sistem Pelayanan Kartu Berlangganan

\section{METODE PENELITIAN}

Untuk mencapai tujuan penelitian ini, dibuat suatu metodologi penelitian yang digambarkan pada gambar 1 di bawah ini:

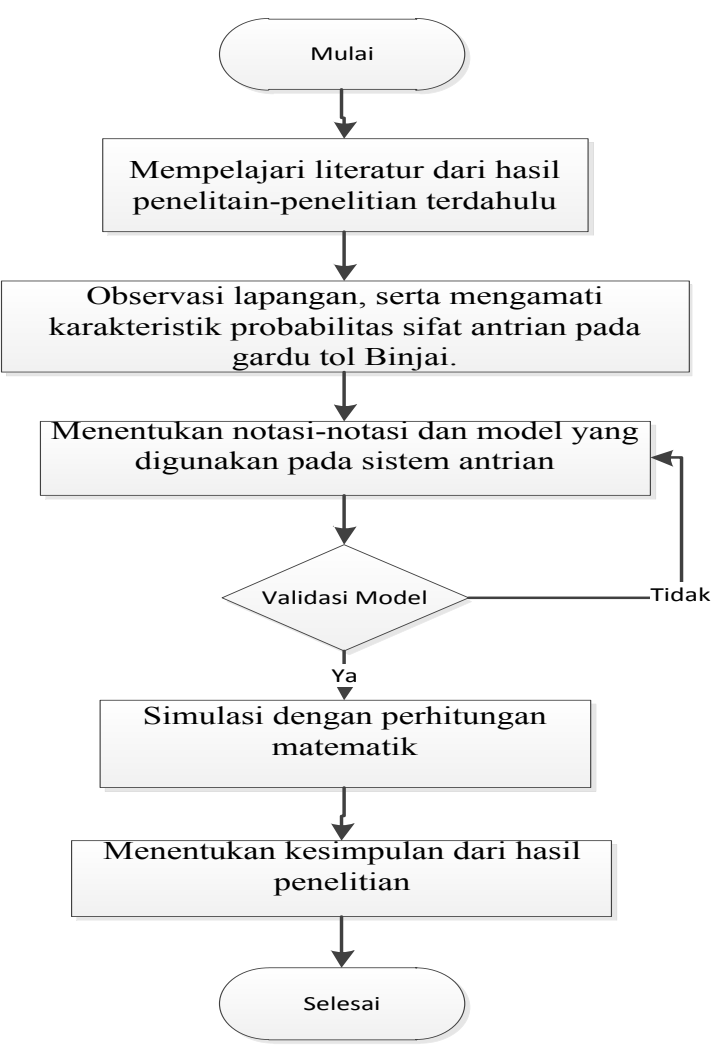

Gambar 1. Flowchart Penelitian 
Adapun keterangan dari tahapan penelitian ini dilakukan untuk mendapatkan hasil yang akurat, yaitu :

1. Mempelajari literatur dari hasil penelitainpenelitian terdahulu

2. Penelitian ini dilakukan dengan melakukan observasi lapangan, serta mengamati karakteristik probabilitas sifat antrian pada gardu tol Binjai.

3. Menentukan notasi-notasi dan model yang digunakan pada sistem antrian

4. Validasi model antrian

5. Melakukan simulasi dengan perhitungan matematik

6. Menentukan kesimpulan dari hasil penelitian

Lokasi survey lapangan dilakukan pada gerbang tol Binjai sebagai titik pengamata lokasi pengumpulan data untuk mencari lama waktu pelayanan, jumlah kendaraan yang memasuki jalan tol dan jumlah pintu tol yang dioperasikan, survey ini dilakukan dengan memprioritaskan waktu pelayanan pada saat terjadi jam sibuk, baik pagi maupun sore, lokasi survey digambarkan pada gambar 2. di bawah ini :

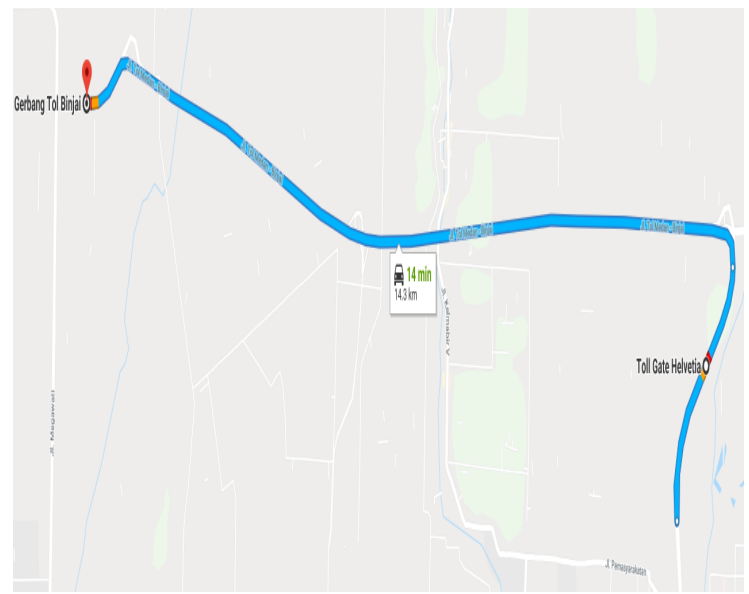

Gambar 2. Lokasi Survey

Jumlah kendaraan yang memasuki jalan tol medan binjai pada hari kerja sekitar 9000 kendaraan pada kedua jalur, dan sekitar 1000 ribu pada hari sabtu dan minggu, sedangkan kondi gerbang saat ini berjumlah 3 gerbang masuk dari Binjai dan gerbang keluar ada sebanyak 3 gerbang, dan begitu juga sebaliknya gerbang masuk dari Medan sebanyak 3 gerbang dan gerbang keluar sebanyak 3 gerbang.

Suatu keadaan nyata dalam kehidupan sehari-hari dapat dilakukan suatu asumsi-asumsi untuk membentuk model matemati, sehingga dapat menyederhanakan model, sehingga dapat diselesaikan dengan dengan baik menggunakan. Adapun Notasi-notasi pada sistem antrian ini digunakan sebagai berikut (Akim Manaor Hara Pardede, Novriyenni, \& Hartono, 2018) :

$$
\begin{array}{ll}
\lambda & : \text { Laju kedatangan } \\
\mu & : \text { Laju pelayanan } \\
\mathrm{C} & : \text { Server } \\
\mathrm{E}[\mathrm{X}] & : \text { Mean batch size } \\
\mathrm{M} & \text { : random variabel } \\
\rho & \text { : Probabilitas server sibuk } \\
\mathrm{L}_{\mathrm{s}} & \text { : Rata-rata pelanggan dalam sistem } \\
\mathrm{L}_{\mathrm{q}} & \text { : Rata-rata pelanggan dalam antrian } \\
\mathrm{W}_{\mathrm{s}} & \text { : Rata-rata waktu tunggu dalam sistem } \\
\mathrm{W}_{\mathrm{q}} & \text { : Rata-rata waktu tunggu dalam antrian }
\end{array}
$$

\section{HASIL DAN PEMBAHASAN}

Untuk lebih jelasnya, perhitungan secara matematik di jelaskan pada bagian dibawah ini :

\section{Perhitungan Tingkat Kedatangan}

Diperoleh jumlah kendaraan 10000 untuk kedua jalur, sehingga bisa diasumsikan 5000 kendaraan perhari, dan 5000/24 jam $=208,33$ kendaraan $/ \mathrm{jam}=$ 209 (Pembulatan)

Kedatangan kendaraan rata-rata $(\lambda)$ :

$$
\lambda=\frac{\sum \lambda}{N}=\frac{209}{3}=69,67 \text { Kendaraan } / \mathrm{jam}
$$




\section{Perhitungan Tingkat Pelayanan}

Perhitungan tingkat pelayanan ditunjukan dalam tabel 1 berikut:

Tabel 1. Waktu pelayanan tiap gardu

\begin{tabular}{cc}
\hline No Gardu & $\begin{array}{c}\text { Rata-rata Waktu Pelayanan } \\
\text { (Detik) }\end{array}$ \\
\hline $\mathbf{1}$ & 8.5 \\
$\mathbf{2}$ & 8.7 \\
$\mathbf{3}$ & 9.4 \\
\hline
\end{tabular}

Waktu pelayanan rata-rata gardu :

- Headway Rata-rata Gardu :

$$
\begin{array}{r}
x=\frac{\sum x}{N}=\frac{8.5+8.7+9.4}{3}=\frac{26,6}{3} \\
=8.87 \text { detik/kendaraan }
\end{array}
$$

- Tingkat Keberangkatan Rata-rata :

$=1 / 8,87$

$=0,11$ kendaraan $/$ detik

- Tingkat Pelayanan Rata-rata Gardu

$$
\mu=\frac{290}{8,87}=32,70=33 \text { Kendaraan } / \mathrm{jam}
$$

\section{Perhitungan Kapasitas Gerbang}

Indikasi yang digunakan untuk menilai suatu sistem pelayanan gerbang tol Binjai-Medan adalah :

a. Jumlah rata-rata kendaraan didalam sistem ( $\mathrm{n}$ )

b. Jumlah kendaraan dalam antrian ( q)

c. Waktu rata-rata dalam sistem ( d )

d. Waktu menunggu dalam antrian ( w )

Pendekatan yang dapat digunakan untuk mengetahui nilai-nilai dari indikasi diatas adalah dengan disiplin antrian FIFO.

Tingkat Kedatangan $(\lambda)=70$ kendaraan/jam Tingkat Pelayanan $(\mu)=406$ kendaraan/jam Jumlah Gardu $(\mathrm{N})=3$

$$
\rho=\frac{\lambda / \mathrm{N}}{\mu}
$$

$$
\begin{gathered}
\rho=\frac{70 / 3}{33} \\
\rho=0,70 \\
\rho<1
\end{gathered}
$$

Dengan nilai $\rho<1$, berarti tidak akan terjadi antrian kendaraan yang panjang, oleh karena itu jumlah gardu tol masih mencukupi.

Oleh karena itu jumlah gerbang tol yang sesuai dengan tingkat kedatangan kendaraan yang ada, untuk memunimumkan biaya atau mengurangi kejadian idle pada Gerbang tol adalah :

$$
\begin{gathered}
1>\frac{\lambda / N}{\mu} \\
1>\frac{70 / N}{33} \\
N=2,12 \\
N=3
\end{gathered}
$$

Jumlah Gerbang $(\mathrm{N})=3$, tetapi dimungkinkan untuk mengurangi pemborosan jumlah gerbang menjadi 2 .

\section{KESIMPULAN}

Adapun kesimpulan dari hasil penelitian ini adalah :

1. Jumlah gerbang tol yang sesuai dengan tingkat kedatangan kendaraan pada Gardu tol Binjai adalah 3, tetapi dimungkinkan untuk mengurangi pemborosan jumlah gerbang menjadi 2.

2. Dengan perhitungan diatas, disimpulkan Jumlah gerbang tol masih sesuai.

3. Probabilitas Gardu sibuk $=<1$ berarti untuk saat ini Gerbang Tol Binjai tidak akan terjadi antrian panjang.

4. Perlu dilakukan analisa selanjutnya pada tahuntahun berikutnya, sehingga probabilitas Gardu Tol dapat selalu dimaksimalkan. 


\section{DAFTAR PUSTAKA}

Akahane, H., \& Kuwahara, M. (1996). A basic study on trip reservation systems for recreational trips on motorways. In Proceedings of the the 3rd World Congress on Intelligent Transportation Systems.

Andika, \& Pardede, A. M. H. (2018). Simulasi Antrian Pelayanan Bank Menggunakan Metode Eksponensial. Jurnal Sistem Informasi Kaputama (JSIK), 2(1), 9-19.

\section{DEPARTEMEN PEKERJAAN UMUM} DIREKTORAT JENDERAL BINA MARGA. (2009). STANDAR Konstruksi dan Bangunan Geometri Jalan Bebas Hambatan Untuk Jalan Tol.

Iskandar, H. (2012). Kapasitas Dasar Jalan Bebas Hambatan (Basic Capacity for Freeway). Pusat Litbang Jalan Dan Jembatan.

Liu, K., Chan, E., Lee, V., Kapitanova, K., \& Son, S. H. (2013). Design and evaluation of tokenbased reservation for a roadway system. Transportation Research Part C: Emerging Technologies. https://doi.org/10.1016/j.trc.2012.09.001

Pardede, A. M. H. (2013). Simulasi Antrian Pelayanan Berkelompok Oleh Banyak Server. Universitas Sumatera Utara.

Pardede, A. M. H., Mawengkang, H., \& Situmorang, Z. (2014). Simulasi Antrian Kedatangan Berkelompok Dengan Pelayanan Weibull Oleh Banyak Server. Jurnal Teknologi Informasi Dan Komunikasi, 3(1), 1-10.

Pardede, A. M. H., Mawengkang, H., Zarlis, M., Tulus, T., Maulita, Y., Fauzi, A., \& N Novriyenni. (2018). Framework For Patient
Service Queue System For Decision Support System on Smart Health Care. International Journal of Engineering and Technology (UAE), 7(2.13), 337-340. https://doi.org/10.14419/ijet.v7i2.13.16915

Pardede, A. M. H., Novriyenni, \& Hartono, R. (2018). Simulasi Antrian Pelayanan Nasabah Bank Menggunakan Metode Hyperexponential. Journal Information System Development (ISD), 3(1), 33-43.

Pasirulloh, M. A., \& Suryani, E. (2017). Pemodelan Dan Simulasi Sistem Industri Manufaktur Menggunakan Metode Simulasi Hybrid (Studi Kasus: PT. Kelola Mina Laut). Jurnal Teknik ITS, 6(2). https://doi.org/10.12962/j23373539.v6i2.231 41

Purnomo, Y., \& Wulandari, A. (2017). SEBARAN FASILITAS PELAYANAN PUBLIK DAN PILIHAN MASYARAKAT DI KECAMATAN PONTIANAK UTARA, KOTA PONTIANAK. LANGKAU BETANG: JURNAL ARSITEKTUR. https://doi.org/10.26418/lantang.v4i2.23249

Saragih, C. A. P., \& Pardede, A. M. H. (2018). Simulasi Antrian Pelayanan Bank Dengan Menggunakan Metode Gamma. Jurnal Teknik Informatika Kaputama (JTIK), 2(1), 14-23.

Simamora, R. J., \& Jamaluddin. (2017). SIMULASI MONTE CARLO DENGAN MODEL PERSEDIAAN STOKASTIK PADA PT.BINGEI MEDAN. Jurnal Teknik Informatika Kaputama (JTIK), 1(2), 30-35.

Sodikin. (2006). KAJIAN MASALAH ANTRIAN PADA SISTEM PENGUMPULAN TOL 
KONVENSIONAL TERHADAP

RANCANGAN SISTEM PENGUMPULAN

TOL ELEKTRONIK. PROGRAM

PASCASARJANA UNIVERSITAS

DIPONEGORO SEMARANG.

Wang, Y., Kim, D., Kim, S.-H., \& Lee, H. (2017).

Designing highway access control system

using multi-class $\mathrm{M} / \mathrm{G} / \mathrm{C} / \mathrm{C}$ state dependent

queueing model and cross-entropy method. In

2017 Winter Simulation Conference (WSC)

(pp. 1443-1454). IEEE.

https://doi.org/10.1109/WSC.2017.8247887

Winarsih, N., \& Kusumaningrum, J. (2013).

ANALISIS KAPASITAS GERBANG TOL

KARAWANG BARAT. In Proceeding

PESAT (Psikologi, Ekonomi, Sastra,

Arsitektur \& Teknik Sipil) (pp. 67-63).

Wong, J. T. (1997). Basic concepts for a system for advance booking for highway use. Transport Policy. https://doi.org/10.1016/S0967-

070X(97)00006-1 